Check for updates

The BMJ

Cite this as: $B M / 2022 ; 376: 0493$ http://dx.doi.org/10.1136/bmj.0493 Published: 25 February 2022

\title{
Covid-19: Vaccine programme a success, but staff burnout is a major risk, auditors warn
}

\section{Gareth lacobucci}

The UK's covid-19 vaccination programme has been a success and has delivered value for money so far, but future success could be undermined by staff burnout and constrained capacity, the UK's public spending watchdog has warned.

In a report published on 25 February the National Audit Office said the programme had successfully achieved unprecedented moving targets, helping to save lives and reduce serious illness and hospital admissions. ${ }^{1}$ But it cautioned, "There are considerable risks to the programme's continuing success. There are still around 3.7 million unvaccinated adults who are unevenly spread throughout the population. Our assessment is that staffing remains a major risk, due to staff burnout, and the lack of surplus capacity in the healthcare system generally."

Gareth Davies, head of the NAO, said, "The vaccine programme has been successful in getting early access to what were brand new covid-19 vaccines, securing supply of them, and administering them to a large proportion of the population at unprecedented speed.

"The programme must now redouble its efforts to reach those who are not yet vaccinated while also considering what a more sustainable model will involve as it moves out of its emergency phase."

By the end of October $85 \%$ of adults had received two doses of the vaccine, and more than 87 million doses had been administered in total. This was over six times the number in the previous annual flu vaccination programme and exceeded the NHS's initial planning assumption that $75 \%$ of adults would take two doses, the NAO said.

The watchdog singled out primary care for praise, noting that GPs and community pharmacists had ended up administering many more vaccine doses than originally planned: $71 \%$ up to the end of October 2021, against a planned 56\%.

"In our local case study interviews, we heard about the goodwill, flexibility, and dedication needed to set up and run vaccination sites at such pace and scale," the NAO said.

Up to the end of October the vaccination programme had spent $€ 5.6 \mathrm{bn}(€ 67 \mathrm{bn}$; $\$ 76 \mathrm{bn}$ ) out of the total available funding of $£ 8.3 \mathrm{bn}$ for the two years to the end of March 2022, including £2.9bn to purchase vaccines and $€ 2.2 \mathrm{bn}$ on deploying them.

The watchdog added that the UK Vaccine Taskforce's "proactive" decision to purchase several different potential vaccines early on and then maintain this supply was crucial to the successful rollout of the programme.
Auditors estimated that vaccine wastage in England by the end of October 2021 was 4.6 million doses, or $4 \%$ of the total supply, much lower than the $15 \%$ to $20 \%$ initially assumed. But there was a particular challenge with expiring doses of AstraZeneca's vaccine after the Joint Committee on Vaccination and Immunisation recommended that people aged under 40 should preferably not be offered it, meaning that about 1.9 million doses delivered to local sites had to be written off.

In the future, the NAO said, the Department of Health for England will need to consider the best organisational structure for the vaccine programme and how future costs and other resources may need to differ from the current emergency response.

It added that NHS England and NHS Improvement should "take additional steps to manage the vaccine workforce and its welfare sustainably" and to examine how the programme can minimise any potential adverse effects on other health and public health services.

Alongside this, further efforts were needed to increase uptake in groups that had lower rates than the rest of the population, such as some ethnic minority groups, young people, and pregnant women.

\section{Davies G. The rollout of the covid-19 vaccination programme in England. National Audit Office. Feb 2022. https://www.nao.org.uk/report/the-roll- out-of-the-covid-19-vaccine-in-england.}

This article is made freely available for personal use in accordance with BMJ's website terms and conditions for the duration of the covid-19 pandemic or until otherwise determined by BMJ. You may download and print the article for any lawful, non-commercial purpose (including text and data mining) provided that all copyright notices and trade marks are retained. 